\title{
Antibodies for strain 2117-like vesiviruses (caliciviruses) in humans
}

\author{
Barbara Di Martino $^{a}, *$, Federica Di Profio ${ }^{a}$, Gianvito Lanave ${ }^{b}$, Simona De Grazia ${ }^{c}$, \\ Giovanni M. Giammanco ${ }^{\mathrm{c}}$, Antonio Lavazza ${ }^{\mathrm{d}}$, Canio Buonavoglia ${ }^{\mathrm{b}}$, Fulvio Marsilio ${ }^{\mathrm{a}}$, \\ Krisztián Bányai ${ }^{\mathrm{e}}$, Vito Martella ${ }^{\mathrm{b}}$ \\ ${ }^{a}$ Faculty of Veterinary Medicine, Università degli Studi di Teramo, Italy \\ ${ }^{\mathrm{b}}$ Faculty of Veterinary Medicine, Università Aldo Moro di Bari, Valenzano, Italy \\ c Department of Scienze per la Promozione della Salute "G. D'Alessandro", Università degli Studi di Palermo, Italy \\ ${ }^{\mathrm{d}}$ Centro di Referenza Nazionale per le Malattie Virali dei Lagomorfi, Istituto Zooprofilattico Sperimentale della Lombardia e dell'Emilia Romagna, Italy \\ e Institute for Veterinary Medical Research, Centre for Agricultural Research, Hungarian Academy of Sciences, Budapest, Hungary
}

\section{A R T I C L E I N F O}

\section{Article history:}

Received 22 June 2015

Received in revised form 13 August 2015

Accepted 21 August 2015

Available online 28 August 2015

\begin{abstract}
A B S T R A C T
The vesivirus strain 2117 has been identified as contaminant of bioreactors used for production of human drugs, due to possible contamination of the reagents used for cell cultivation. Using an ELISA assay, antibodies specific for 2117-like viruses were detected in 32/410 (7.8\%) human sera, indicating exposure to these viruses.
\end{abstract}

(C) 2015 Elsevier B.V. All rights reserved.

Keywords:

Caliciviruses

Vesivirus strain 2117

Antibodies

Humans

The Caliciviridae are small non-enveloped viruses approximately of $35 \mathrm{~nm}$ in diameter with single-stranded, positive-polarity RNA genomes of $7.4-8.3 \mathrm{~kb}$. The family includes the genera Vesivirus, Lagovirus, Norovirus, Sapovirus and Nebovirus (Carstens, 2010). In addition, a number of unclassified caliciviruses have been identified in mammalians, avians and fishes (Cubitt and Barrett, 1985; Farkas et al., 2008; L'Homme et al., 2009; Wolf et al., 2011; Liao et al., 2014; Mikalsen et al., 2014)

In 2003, a novel calicivirus, the vesivirus (VeV) strain 2117, was identified incidentally as a contaminant in Chinese Hamster Ovary (CHO) cell cultures by a German pharmaceutical company (Oehmig et al., 2003). Possible sources of contamination included reagents commonly used for cell cultivation, such as porcine-derived trypsin or fetal bovine serum. Interestingly, strain 2117 showed about $72 \%$ nucleotide (nt) identity in the full-length genome to the prototype canine calicivirus strain 48 identified in Japan 1990 in a 2-monthold pup with intermittent watery diarrhea (Mochizuki et al., 1993).

Contamination of $\mathrm{CHO}$ cell cultures by the VeV strain 2117 was documented in three additional episodes, in 2008 and 2009 in Allston, Massachusetts, USA, and in 2008 in Geel, Belgium. The 2008-2009 contamination in the USA was esti-

\footnotetext{
* Corresponding author. Fax: +390861 266885.

E-mail address: bdimartino@unite.it (B. Di Martino).
}

mated to cost $\$ 100-300$ million in loss of revenues to the biotech company Genzyme, due to interruption of the production of Cerezyme (imiglucerase) and Fabrazyme (agalsidase $\beta$ ), i.e. drugs for extremely rare and life-threatening diseases, Gaucher's disease and Fabry's disease, respectively (Allison, 2010). In addition, Genzyme's contamination raised concerns about potential exposure of humans to these novel viruses, as VeVs are able to cross easily the host species barrier (Smith et al., 1998b). However, there was no evidence that the contaminant virus harmed people and the only inconvenience was the diminished productivity of the $\mathrm{CHO}$ cell lines. More recently, screening of faecal specimens from household and shelter dogs in Europe has led to the identification of novel canine VeVs (Martella et al., 2015) more genetically similar in their genome (89-90\% nt) to the VeV strain 2117 , than to the prototype canine strain 48 (71\% nt). The 2117 -like VeVs were detected at high prevalence $(64.8 \%)$ in the rectal swabs of healthy dogs housed in shelters. Accordingly, as these viruses appear to be common in dogs, and shed trough the faeces, it may be hypothesized that faecal contamination of canine origin may also be a source of exposure to these VeVs for humans.

In order to assess if humans are exposed to 2117-like VeVs, we screened an age-stratified collection of human sera $(n=410)$ collected between 2010 and 2011 by using an ELISA assay based on the recombinant capsid protein (VP1) of a 2117-like virus expressed in baculovirus system. Human sera were collected 


\section{A}

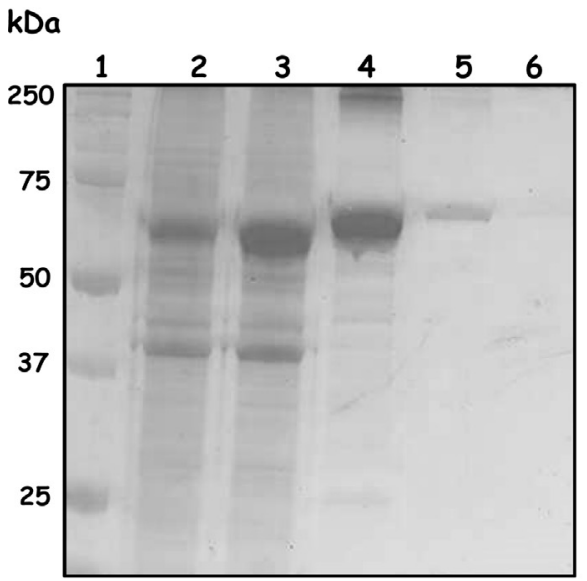

B

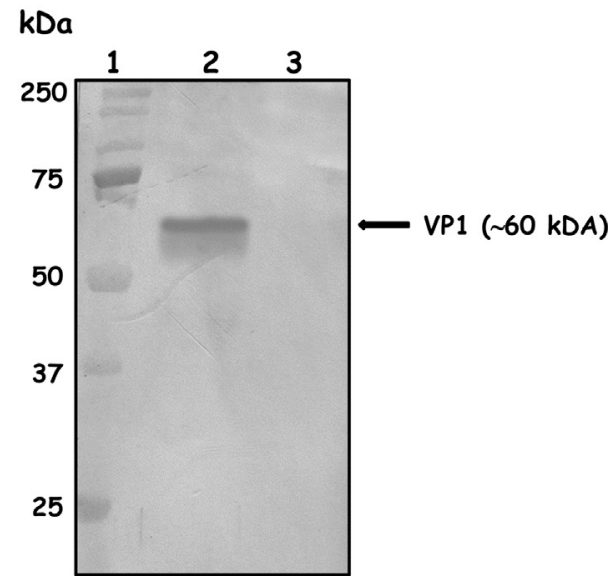

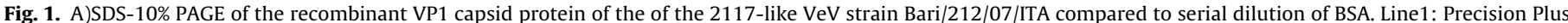

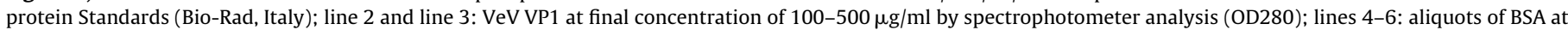

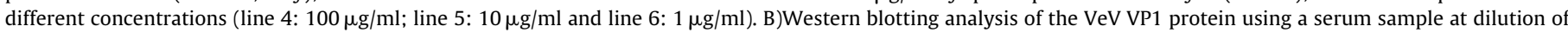

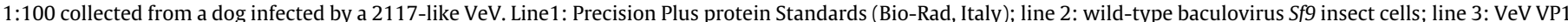
purified from the supernatants of Sf9insect cells.

randomly from both inpatients and outpatients presenting with various pathologies, at the Microbiology Unit of the University Hospital "P. Giaccone" of Palermo (Italy), between September 2010 and June 2011. Risk factors were not considered when collecting the human sera. All the patients were enrolled in the study after giving informed consent. Also, a total of 611 serum samples collected in 2011 from pigs of various age and of different Italian geographic regions were included in the screening, to address the hypothesis that contamination of $\mathrm{CHO}$ was originated from cell culture reagents, such as porcine-derived trypsin.

The recombinant baculovirus carrying the gene for the viral capsid protein (VP1) of the canine strain Bari/212/07/ITA (GenBank accession number JN204722) (Martella et al., 2015) was obtained as previously described (Di Martino et al., 2010). Briefly, the full-length VP1 (ORF2) was cloned into the pRN16 vector (kindly provided by Prof. Polly Roy) and transfection was performed with triple cut linearized AcNPV DNA (BD Biosciences, San Diego, CA). The recombinant baculovirus was selected using X-Gal blue/white screening and plaque purified on Spodoptera frugiperda (Sf21) cells. For large-scale production of the antigen, $100 \mathrm{ml} S f 9$ cell $\left(1 \times 10^{6}\right.$ cell $/ \mathrm{ml}$ ) suspension culture were infected with the recombinant baculovirus at a multiplicity of infection of three plaque forming units/cell. The VP1 protein was isolated from the culture medium of infected cells at $48 \mathrm{~h}$ post-infection by centrifugation at $4000 \mathrm{rpm}$ for $20 \mathrm{~min}$. After purification by rate-zonal centrifugation on a discontinuous 20-60\% (wt/vol) sucrose gradient, the collected fractions were dialyzed against PBS, and the protein concentration was determined by measuring the optical density at $280 \mathrm{~nm}\left(\mathrm{OD}_{280}\right)$ and visually by running aliquots on SDS-10\% PAGE containing bovine serum albumin (BSA) standards (Fig. 1A). The antigenicity of the recombinant VP1 was confirmed by Western blotting (WB), using field sera collected from dogs infected by a 2117-like VeV (Martella et al., 2015) (Fig. 1B). Antigenic cross-reactivity between VeV antigen and other human or porcine caliciviruses was ruled out in WB using specific rabbit hyperimmune sera raised against GIV.2 NoV and St-Valerien-like virus (SVLV) virus-like particles (VLPs) and by an antigen-ELISA kit (Ideia Norovirus, Oxoid, Basingstroke, UK) specific for human NoVs of genogroups GI and GII. The GIV.2 and the SVLVs-specific rabbit antisera did not show reactivity in WB analysis using antigen concentrations of $1 \mu \mathrm{g} / \mathrm{ml}$ to $100 \mu \mathrm{g} / \mathrm{ml}$ whilst the VeV VP1 was not detected by the commercial antigen-
ELISA kit at concentrations as high as $100 \mu \mathrm{g}$ of protein per ml. For the development of the antibody-detection ELISA, mock infected cells and VeV VP1 antigen (final concentration of $1 \mu \mathrm{g} / \mathrm{ml}$ ) were coated onto 96 well EIA plates (Costar, Italy) at $100 \mu$ l per well in carbonate-bicarbonate buffer $(0.05 \mathrm{M}, \mathrm{pH} 9.6)$ and incubated at $4{ }^{\circ} \mathrm{C}$ overnight (Di Martino et al., 2012, 2014). After blocking with $2 \%$ BSA in phosphate buffered saline (PBS) buffer at room temperature for two hours, the antigen-coated microplates were incubated with $100 \mu$ l of human or swine serum samples respectively diluted to $1: 100$ and $1: 50$ in $1 \%$ dried milk (Blotto)-PBS, at $37^{\circ} \mathrm{C}$ for $1 \mathrm{~h}$. Plates were washed five times in PBS with $0.1 \%$ tween 20 (PBS$\mathrm{T})$ and then incubated with horseradish peroxidase-conjugated goat anti-human immunoglobulin G (IgG) (Sigma-Aldrich, Italy) or with horseradish peroxidase-conjugated goat anti-swine IgG (Sigma-Aldrich, Italy) at 1:5,000 dilution, for $30 \mathrm{~min}$ at $37^{\circ} \mathrm{C}$. The reaction was developed with the addition of $100 \mu$ l per well of $2,2^{\prime}$ azino-di-(3-ethylbenzthiazoline-6-sulfonate) (ABTS) substrate for $15 \mathrm{~min}$ and stopped adding an equal volume of $1 \mathrm{M}$ phosphoric acid. Absorbance was measured at $405 \mathrm{~nm}$ using a multiskan automatic plate reader (ThermoLabsystems, Finland). The cut-off point of the tests $\left(\mathrm{OD}_{405} \geq 0.5\right)$ was established as the mean of the $\mathrm{OD}_{405}$ readings of 50 serum samples negative in $\mathrm{WB}$ for the presence of VeV-specific antibodies, plus 2 standard deviations. For each tested sample, a positive/negative ratio $\left(\mathrm{OD}_{405}\right.$ of $\mathrm{VeV}$ antigen $/ \mathrm{OD}_{405}$ of mock infected cells) $\geq 2.0$ was used to evaluate the background binding.

Out of 410 human sera, a total of 32 sera (7.8\%) reacted with the VeV antigen at a dilution of $1: 100$ with an $\mathrm{OD}_{405}$ ranging from 0.5 to 1.2 (mean $\mathrm{OD}_{405}$ of 0.8 ). The prevalence of 2117 -like VeVspecific antibodies was $5.3 \%$ in persons $<1-20$ years of age and it increased to $8.0 \%$ in the $21-40$ year age class. This rate tended to be stable in the $41-60$ year (8.6\%) and in the $61-80$ year age class $(8.2 \%)$, declining to $6.8 \%$ in persons $>80$ years of age (Fig. 2 ). There was no statistically significant difference comparing the various age classes by Chi Square Test analysis. Interestingly, none of the tested porcine sera showed reactivity to the $\mathrm{VeV}$ antigen at dilution of $1: 50$

Overall, these findings seem to indicate that humans are exposed to 2117-like VeVs. This group of VeVs is genetically distant from feline caliciviruses and VeVs of marine mammals (Martella et al., 2015), although antigenic cross-reactivity has been docu- 


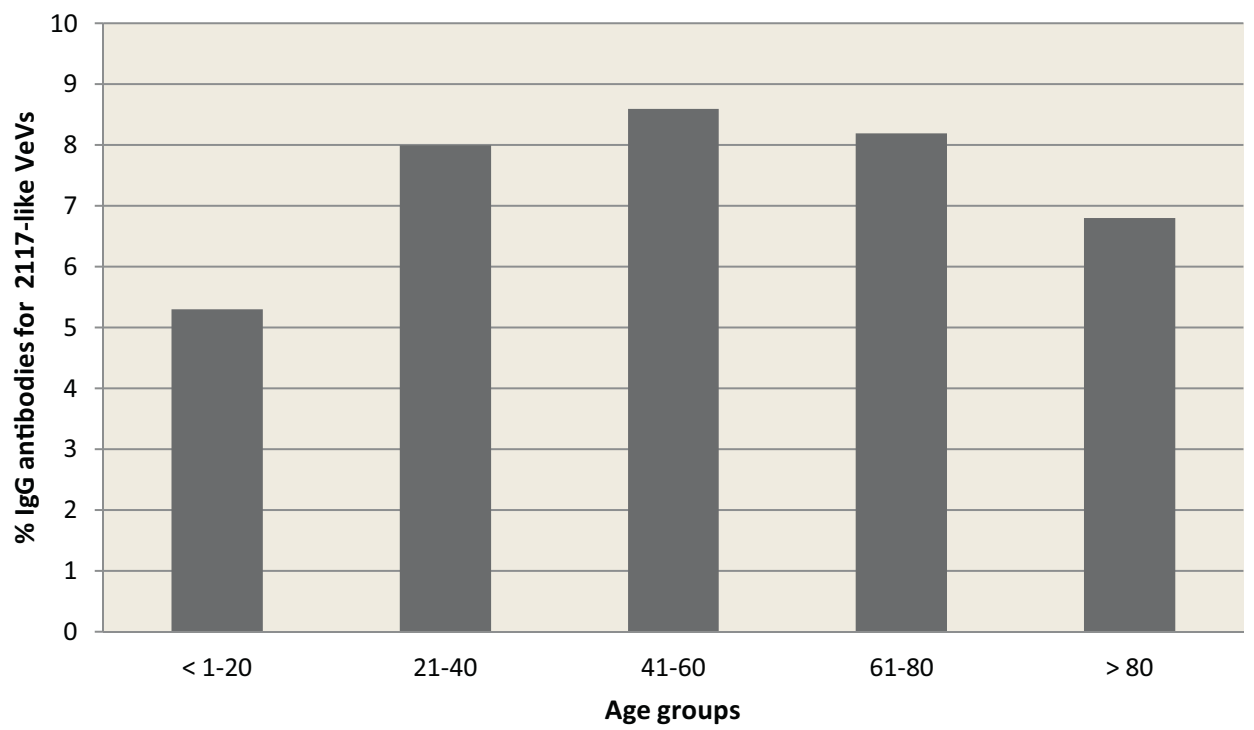

Fig. 2. Age-related prevalence of IgG antibodies to 2117-like VeVs in human sera.

mented between marine and feline VeVs (McClenahan et al., 2012). Accordingly, interference with other VeVs antigenically related to 2117-like viruses should be expected when testing human or animal sera collections. In this regard, it was surprising that none of the 611 porcine sera reacted with the $\mathrm{VeV}$ antigen, indicating firmly that VeVs are uncommon in pigs, at least in the screened animal population. It is worth underlining that several of the serum samples analyzed in this study were serologically positive for the recently described porcine SVLVs, provisionally classified in the novel proposed genus Valovirus (L'Homme et al., 2009; Di Martino et al., 2012). This adds further evidence that the existence of antigenic cross-reactivity is limited to members of the Vesivirus genus. At the same time, our findings indicate that 2117-like VeVs are not common in pigs, at least in the population examined, and raise doubts on the hypothesis that porcine trypsin was the source of CHO contamination.

Whether exposure of humans to VeVs is related to any diseases remains to be assessed. Vesicular lesions on the face, eyes, hands and feet associated with infection by marine VeVs have been documented in biologists working with marine mammals (Smith et al., 1998a,b). In addition, a primate VeV (strain Pan 1) has been isolated from a herpes-like lip lesion in pygmy chimpanzee (Smith et al., 1983) and either natural or experimental infection by VeVs has been documented in primates (Smith et al., 1978, 1985a,b).

In the light of these findings, it is possible to formulate additional hypotheses to explain the repeated contamination events by 2117 -like VeVs reported in the literature, i.e. the introduction in laboratory facilities of 2117-like viruses of canine origin by mechanical transportation with various fomites, or, as a remote possibility, contamination by infected operators actively shedding the virus. These eventualities should be considered when devising strategies for prevention of contamination in biotech facilities.

\section{Conflict of interest}

All Authors declare that there are no financial or other relationships that might lead to a conflict of interest. All authors have seen and approved the manuscript and have contributed significantly to the work.

\section{Acknowledgements}

This work was supported with funds from "Studio sui vesivirus nei cani-Fondi Ateneo 2010" and "Calicivirus nei carnivori e nell'uomo: caratterizzazione molecolare, epidemiologia, implicazioni zoonosiche-PRIN 2008".

\section{References}

Allison, M., 2010. As genzyme flounders, competitors and activist investors swoop. Nat. Biotechnol. 28, 3-4

Carstens, E.B., 2010. Ratification vote on taxonomic proposals to the International Committee on Taxonomy of Viruses (2009). Arch. Virol. 155, 133-146.

Cubitt, W.D., Barrett, A.D., 1985. Propagation and preliminary characterization of a chicken candidate calicivirus. J. Gen. Virol. 66, 1431-1438.

Di Martino, B., Di Profio, F., Ceci, C., Di Felice, E., Green, K.Y., Bok, K., De Grazia, S., Giammanco, G.M., Massirio, I., Lorusso, E., Buonavoglia, C., Marsilio, F., Martella, V., 2014. Seroprevalence of norovirus genogroup IV antibodies among humans, Italy, 2010-2011. Emerg. Infect. Dis. 20, 1828-1832.

Di Martino, B., Di Profio, F., Ceci, C., Martella, V., Lavazza, A., Massirio, I., Marsilio, F., 2012. Seroprevalence of St-Valerien-like caliciviruses in Italian swine. J. Gen. Virol. 93, 102-105.

Di Martino, B., Marsilio, F., Di Profio, F., Lorusso, E., Friedrich, K.G., Buonavoglia, C., Martella, V., 2010. Detection of antibodies against norovirus genogroup GIV in carnivores. Clin. Vaccine Immunol. 17, 180-182.

Farkas, T., Sestak, K., Wei, C., Jiang, X., 2008. Characterization of a rhesus monkey calicivirus representing a new genus of Caliciviridae. J. Virol. 82, 5408-5416.

L'Homme, Y., Sansregret, R., Plante-Fortier, E., Lamontagne, A.M., Ouardani, M. Lacroix, G., Simard, C., 2009. Genomic characterization of swine caliciviruses representing a new genus of Caliciviridae. Virus Genes 39, 66-75.

Liao, Q., Wang, X., Wang, D., Zhang, D., 2014. Complete genome sequence of a novel calicivirus from a goose. Arch. Virol. 159, 2529-2531.

Martella, V., Pinto, P., Lorusso, E., Di Martino, B., Wang, Q., Larocca, V., Cavalli, A., Camero, M., Decaro, N., Bányai, K., Saif, L.J., Buonavoglia, C., 2015. Detection and full-length genome characterization of novel canine vesiviruses. Emerg. Infect. Dis., http://dx.doi.org/10.3201/eid2108.140900, In press.

McClenahan, S.D., Bok, K., Sosnovtsev, S.V., Neill, J.D., Burek, K.A., Beckmen, K.B., Smith, A.W., Green, K.Y., Romero, C.H., 2012. Expression and self-assembly of virus-like particles from two genotypes of marine vesiviruses and development of an ELISA for the detection of antibodies. Vet. Microbiol. 142, 184-192.

Mikalsen, A.B., Nilsen, P., Frøystad-Saugen, M., Lindmo, K., Eliassen, T.M., Rode, M., Evensen, O., 2014. Characterization of a novel calicivirus causing systemic infection in atlantic salmon (Salmo salar L.): proposal for a new genus of caliciviridae. PLoS One 9, e107132.

Mochizuki, M., Kawanishi, A., Sakamoto, H., Tashiro, S., Fujimoto, R., Ohwaki, M.A., 1993. Calicivirus isolated from a dog with fatal diarrhoea. Vet. Rec. 132 221-222.

Oehmig, A., Büttner, M., Weiland, F., Werz, W., Bergemann, K., Pfaff, E., 2003. Identification of a calicivirus isolate of unknown origin. J. Gen. Virol. 84, 2837-2845.

Smith, A.W., Prato, C.E., Skilling, D., 1978. Caliciviruses infecting monkeys and possibly man. Am. J. Vet. Res. 39, 287-289. 
Smith, A.W., Skilling, D.E., Ensley, P.K., Benirschke, K., Lester, T.L., 1983. Calicivirus isolation and persistence in a pygmy chimpanzee (Pan paniscus). Science 221, 79-81.

Smith, A.W., Skilling, D.E., Anderson, M.P., Benirschke, K., 1985a. Isolation of primate calicivirus pan paniscus type 1 from a douc langur (Pygathrix nemaeus L.). J. Wild Dis. 21, 426-428.

Smith, A.W., Skilling, D.E., Benirschke, K., 1985b. Calicivirus isolation from three species of primates: an incidental finding. Am. J. Vet. Res. 46, 2197-2199.
Smith, A.W., Berry, E.S., Skilling, D.E., Barlough, J.E., Poet, S.E., Berke, T., Mead, J., Matson, D.O., 1998a. In vitro isolation and characterization of a calicivirus causing a vesicular disease of the hands and feet. Clin. Infect. Dis. 26, 434-439.

Smith, A.W., Skilling, D.E., Cherry, N., Mead, J.H., Matson, D.O., 1998b. Calicivirus emergence from ocean reservoirs: zoonotic and interspecies movements. Emerg. Infect. Dis. 4, 13-20.

Wolf, S., Reetz, J., Otto, P., 2011. Genetic characterization of a novel calicivirus from a chicken. Arch. Virol. 156, 1143-1150. 